\title{
Have You Seen My Teeth? A Case with an Extraordinary Radiologic Finding
}

\author{
Serdar Evman ${ }^{1} \quad$ Yelda Tezel $^{2} \quad$ Melis Demirag Evman $^{3} \quad$ Çagatay Tezel ${ }^{1}$ \\ ${ }^{1}$ Department of Thoracic Surgery, Sureyyapasa Chest Diseases and \\ Thoracic Surgery Training and Research Hospital, Istanbul, Turkey \\ ${ }^{2}$ Department of Pulmonology, Haydarpasa Numune Training and \\ Research Hospital, Istanbul, Turkey \\ Address for correspondence Serdar Evman, MD, MSc, Süreyyapaşa \\ Gögüs Hastalıkları ve Gögüs Cerrahisi, Egitim ve Araştırma Hastanesi, \\ D blok Başıbüyük, Maltepe Istanbul, Turkey \\ (e-mail:sevman13@yahoo.com).
}

${ }^{3}$ Department of Otorhinolaryngology, Marmara University Hospital, Istanbul, Turkey

Surg J 2016;2:e49-e50.

\begin{abstract}
Keywords

- bronchoscopy

- computed tomography

- foreign body

- trachea
\end{abstract}

Endobronchial foreign body aspiration is rare in the adult population with normal cognitive and mental functions. ${ }^{1,2}$ According to the nature of the aspirated object and the baseline health status of the patient, it can even be fatal, especially for pediatric patients. ${ }^{2}$ Rigid bronchoscopy still plays the main role for the definite diagnosis and removal of the aspirated material.

\section{Case Report}

A 55-year-old man was admitted to the emergency department with acute onset of dyspnea following a hypotensive syncope attack at home. Physical examination revealed no hypotension or fever, Glasgow Coma Score of 15, and severe dyspnea with diffuse stridor and hypoxemia (arterial $\mathrm{PaO}_{2}$ $=59 \mathrm{~mm} \mathrm{Hg}, \mathrm{SaO}_{2}=83 \%$ ) on admission. There was no history of any known respiratory diseases.

Cranial and thoracic computed tomography revealed no pathologic sign of traumatic cranium fracture or intracranial hemorrhage but confirmed an opaque foreign body localized at the carina partially obstructing the right main bronchus (- Figs. 1A, B). Posteroanterior skull radiograph confirmed the missing part of a dental prosthesis (-Fig. 2) that probably fragmented during the syncope attack, which was immediately removed under rigid bronchoscopy (-Fig. 3). The etiology of the hypotensive episode could not be established. The patient was discharged on the same day and was referred to the cardiology outpatient clinic for further investigation.

\section{Discussion}

A wide variety of aspirated items, which may demonstrate regional, seasonal, or cultural dispersion, are published in the literature. ${ }^{1-3}$ Craniofacial trauma, medical interventions like endotracheal intubation, or conditions linked to altered consciousness such as mental retardation, dementia, or intoxication are among the known risk factors. ${ }^{2,4,5}$ The aspiration of prostheses or teeth during trauma, accidents, and dental procedures has been reported in the literature. ${ }^{4-6}$ Tooth aspiration during medical interventions such as endotracheal intubation has also been described. ${ }^{7}$ received

October 27, 2015

accepted after revision

February 5, 2016
DOI http://dx.doi.org/

10.1055/s-0036-1580707. ISSN 2378-5128.
Copyright $\odot 2016$ by Thieme Medical Publishers, Inc., 333 Seventh Avenue, New York, NY 10001, USA. Tel: +1(212) 584-4662.
License terms

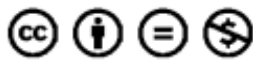




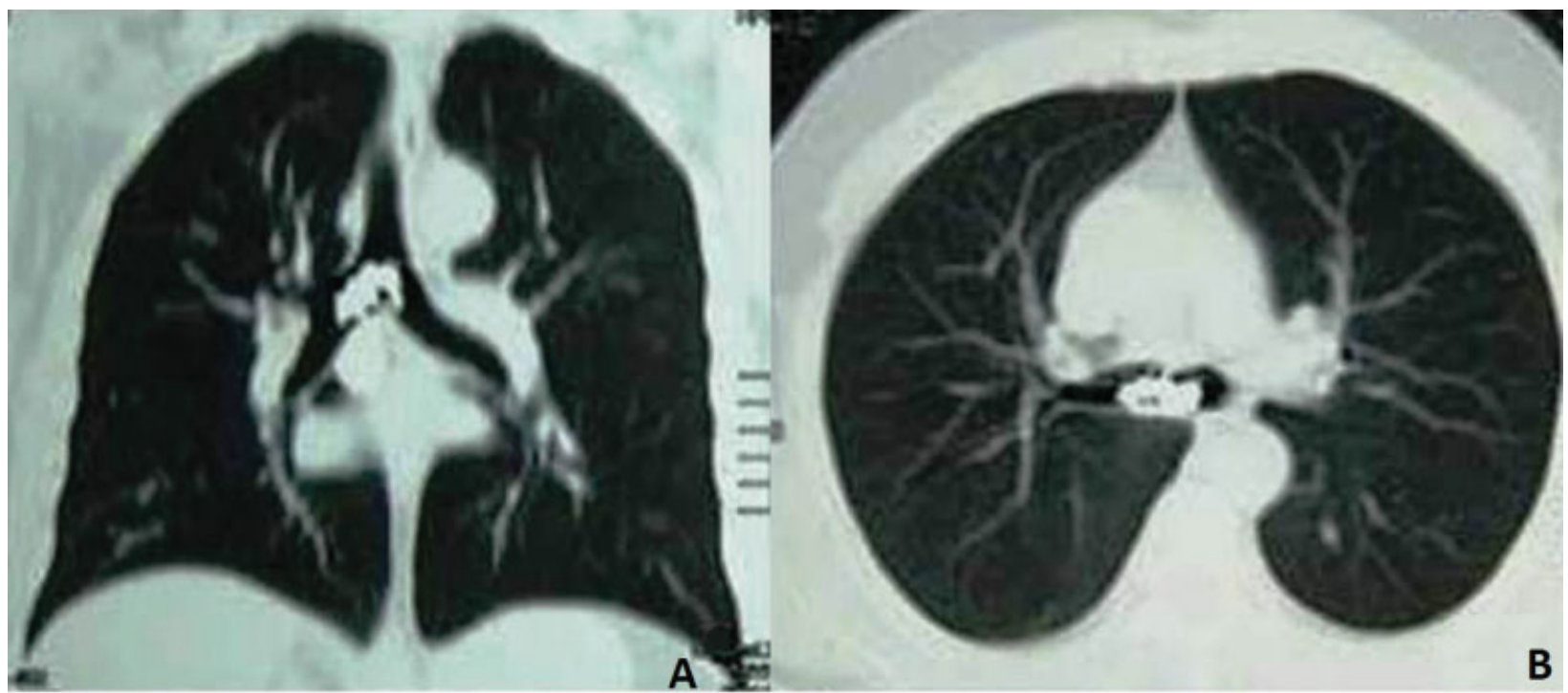

Fig. 1 (A, B) Chest tomography showing aspirated foreign body at the carina, extending into right main bronchus.

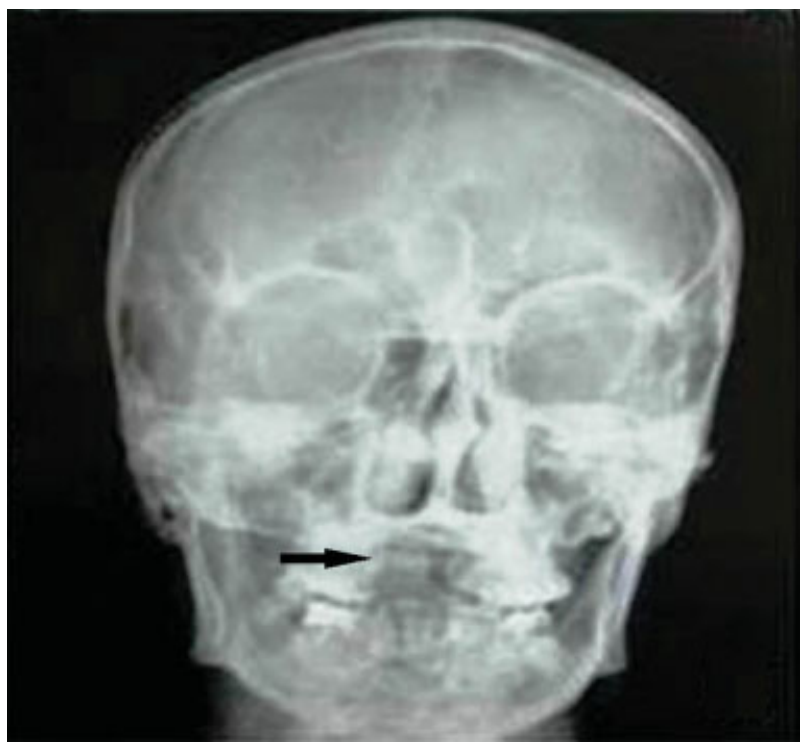

Fig. 2 Skull X-ray demonstrating absence of upper incisor teeth (arrow).

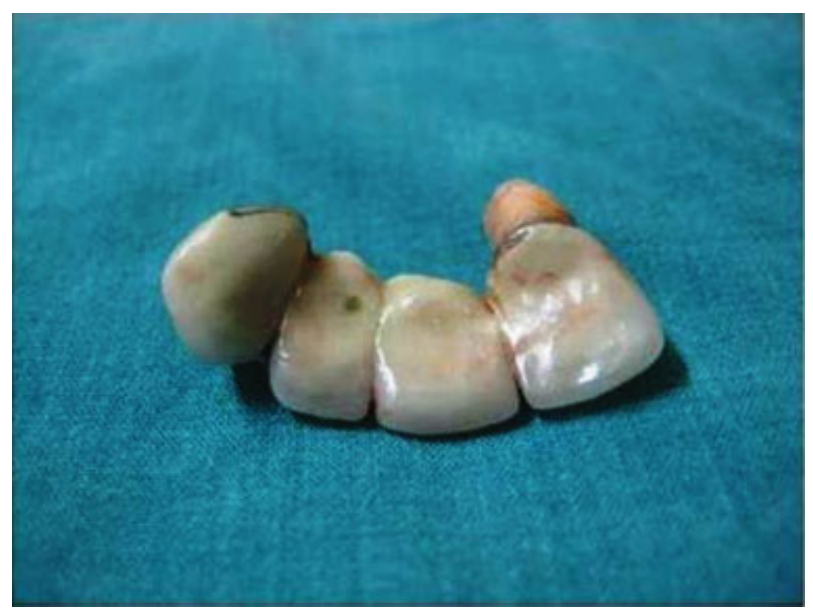

Fig. 3 Removed dental plate.
The right main bronchus, like in our case, is the most common site for aspiration, owing to its anatomical position and the slight angulation of the trachea toward the right side. The most helpful diagnostic methods are the objective complaint of witnessed aspiration and the physical examination of the patient, but radiologic assessment is essential and should be performed if there is any suspicion of foreign body aspiration. Rigid bronchoscopy is the long-established gold standard treatment of choice. ${ }^{3,5}$

The acute onset of dyspnea following trauma may be caused by an intracranial hemorrhage, pneumothorax, or a foreign body occluding the airway. Rapid physical examination of patients with severe acute dyspnea is vital for preventing morbidity and mortality.

\section{Conflict of Interest}

None

\section{References}

1 Ilan O, Eliashar R, Hirshoren N, Hamdan K, Gross M. Turban pin aspiration: new fashion, new syndrome. Laryngoscope 2012; 122(4):916-919

2 Fidkowski CW, Zheng H, Firth PG. The anesthetic considerations of tracheobronchial foreign bodies in children: a literature review of 12,979 cases. Anesth Analg 2010;111(4):1016-1025

3 Trout AT, Towbin AJ. Seasonal foreign bodies: the dangers of winter holiday ornamentation. Pediatr Radiol 2014;44(12):1610-1616

4 Cossellu G, Farronato G, Carrassi A, Angiero F. Accidental aspiration of foreign bodies in dental practice: clinical management and prevention. Gerodontology 2015;32(3):229-233

5 Mahajan JK, Rathod KK, Bawa M, Rao KL. Tracheobronchial foreign body aspirations. Lessons learned from a 10-year audit. J Bronchology Interv Pulmonol 2011;18(3):223-228

6 Kumar N, Goyal H, Bindra A, Goyal K. Management of aspirated tooth in an adult head injury patient: report of two cases. Saudi J Anaesth 2014;8(2):276-278

7 Ostrinsky Y, Cohen Z. Images in clinical medicine. Tooth aspiration. N Engl J Med 2006;354(24):e25 